\title{
Cross-Cultural Differences in the Use of English Affective Disjunct in Personal Commentary Discourse*
}

\author{
YANG Zhu \\ Southwest University, Chongqing, China
}

\begin{abstract}
This paper describes and explains cross-cultural differences in the use of English affective disjunct in media-borne personal commentary discourse. In English, affective disjunct is a syntactically disjunctive element that expresses speakers' affective stance toward information. Notably, the use of affective disjunct, carrying strong subjective implication, is conditioned by cultural factors-English users from different cultural backgrounds may use affective disjunct differently. For an illustration, a comparison in this regard is made between two controlled datasets consisting of written English texts of personal commentary discourse produced by advanced Chinese users and advanced American users respectively. The major statistical difference derived therefrom is that the American dataset contains a significantly higher frequency and more types of affective disjunct than does the Chinese dataset. A functional analysis reveals that the use of affective disjunct can actively involve discourse participants, placing an emphasis on the identities of discourse participants as speaker/author and addressee/reader, on their participation in the construction and negotiation of information, and on the shortening of distance between them. This involvement effect is in fact the defining feature of the solidarity face system of culture. Thus, the differences in the use of affective disjunct reflect the observation that the American users are more influenced by solidarity face system than are the Chinese users. The findings have some implication for examining cultural influence on micro-linguistic features in written discourse.
\end{abstract}

Keywords: affective disjunct, cross-cultural difference, involvement, solidarity face system

\section{Introduction}

The use of micro-linguistic resources for self-expression is inextricably influenced by aspects of culture, and studies on such influence have been gaining momentum (Gudykunst \& Ting-Toomey, 1988; Macaulay, 2002; YANG, 2013). Among such resources in English, affective disjunct is particularly noteworthy since it is a syntactically and semantically unique type and most explicitly manifests speakers' subjectivity in information conveyance (Hoye, 1997; Aijmer, 2002; Vold, 2006). Non-propositional and syntactically peripheral, affective disjunct expresses speakers' affective stance toward the propositional content, such as fortunately in Example (1):

Example (1) California, fortunately, has changed a lot since then, and academic freedom is prioritized far higher...

\footnotetext{
* This research is supported by "the Fundamental Research Funds for the Central Universities” (Grant No.: SWU1109042) and "the Doctoral Research Fund of Southwest University" (Grant No. SWU11319).

YANG Zhu, lecturer, Ph.D., School of Foreign Languages, Southwest University.
} 
Affective disjunct as such appears in a wide range of discourse types from casual speech to academic paper. Notably, since it imbues information with subjective meaning, its use is likely to be conditioned by cultural factors. To make explicit the way culture shapes the use of English affective disjunct, this paper presents a treatise on how culture underlies some differences in this regard between speakers from different cultural backgrounds.

It has long been assumed that language is relative to culture and culture is a major dynamic underlying the differences in language system and language use (Whorf, 1956; Geertz, 1973, 1984; Halliday, 1978; Wierzbicka, 1985; Kramsch, 1998; Spencer-Oatey, 2000; Barron, 2005). The aspect of culture as most relevant to patterned differences in language is usually deemed to be anthropological culture. It is the cognitive aspect and deep level of culture, internalized by cultural members as "the collective programming of the mind" (Hofstede, 1980), "habitus" (Bourdieu, 1984), and "culture in the head” (Atkinson, 2004). It remains fairly invariable over time and forms part of individual members' thinking patterns, thus leaving mark on their linguistic behavior (Goodenough, 1981). Anthropological culture becomes the most salient cultural background of language users, constituting the "context of culture" that defines the potential of user's linguistic behaviors (Malinowski, 1923; Fetzer, 2004). The anthropological cultural background of language users tends to be exploited as a heuristic tool to uncover deep-seated differences in language use.

This study documents the influence of culture on the use of English affective disjunct by examining the differences in the use between users from different anthropological cultural backgrounds. An illustrative comparison is made between users from American versus Chinese cultures, and it will show significant differences in the use between them. With reference to a relevant theoretical framework on culture and discourse, it will be argued that the differences reflect an underlying difference in the face systems of culture between the two cultural groups.

\section{Affective Disjunct as a Unique Modal Category}

In English grammar, disjunct is distinguished by structural and semantic criteria from several related notions. Peripheral adverbial labeled as "sentence modifier", "sentence adverb" (Jacobson, 1964) or "sentential adverbial” (Buysschaert, 1982) is what Greenbaum (1969) identified as disjunct (occurring sententially) and conjunct (occurring intersententially), which are separated from adjunct (occurring intrasententially). Among them, while adjunct specifies the circumstance of states of affairs and conjunct connects clauses or sentences, it is disjunct that expresses modal meaning-speakers' attitude toward the content of what is being said (Greenbaum, 1969; Jacobson, 1978). Disjunct in this sense includes both "disjunct” and "subjunct" in Quirk, Greenbaum, Leech, and Svartvik's (1985) terms, and is also referred to as "stance adverbial” (Biber, Johansson, Leech, Conrad, \& Finegan, 2000) and “modal adjunct” (Halliday, 1994).

In congruent with being syntactically peripheral (optional), disjunct invariably forms a WH-island (Chomsky, 1984) and cannot pass it-cleft or WH-cleft test unless when it is "pied-piped” with another element. By contrast, adjunct is circumstance-restrictive and is deemed as obligatory adverbial (Buysschaert, 1982; Quirk et al., 1985), allowing WH-movement and it-cleft or WH-cleft test. Conjunct, though not allowing WH-movement like disjunct, is semantically different.

Disjunct expresses modal meaning or modality, which is derived from the relativization of the existence of entities and states to a set of possible worlds in philosophy and logic (Perkins, 1983; Kiefer, 1998; Palmer, 2001). Modality in the linguistic sense is often approached from the perspective of speaker's judgment on a 
state of affairs or its possibility of being otherwise. Among the various types of modality ever proposed, an overall distinction needs to be made between objective modality and subjective modality. In Kiefer's (1998) explanation, objective modality is "part of the description of the world" while subjective modality is "the expression of the speaker's beliefs" (p. 594). In other words, objective modality is seen as the logical relation between a proposition and the world, while subjective modality is seen as the relation between the speaker and the proposition. Notably, it is subjective modality that is commonly held to be the more essential aspect of modality in most natural languages (Lyons, 1995; Hoye, 1997; Palmer, 2001). Subjective modality (also "subjectivity") is usually dealt with as an interpersonal aspect of utterance meaning (Halliday, 1994; Hyland, 1999; Hunston \& Thompson, 2000; Martin \& White, 2005).

Disjunct is expressive of subjective rather than objective modality, since it lies outside the propositional content. This essential characteristic separates it from the other modal devices, such as modal lexical or auxiliary verbs, adjectival and nominal modal expressions (Perkins, 1983). These devices are likely to be proposition-internal and their modal meanings are objectified in utterances (Lyons, 1995). Only disjunct (consisting usually of adverbs and interjections) carries modal meaning that is explicitly attributable to the speaker, since it is dissociated the most from the grammatical structure and from the propositional meaning (Hoye, 1997). This is explicitly reflected in the flexible placement and independent tonal shape of disjunct (see Examples (2)-(3)).

Examples (2) There are hopefully some bilateral meetings at the sidelines of the summit to discuss bilateral... issues.

Examples (3) Unfortunately, this perception of our mortality does not always motivate acts of virtue...

It then follows that focusing on disjunct to examine subjective modal meaning is more reliable than taking a lexical approach, in that adopting both syntactic and semantic criteria can avoid the arbitrariness in specifying lexical items that are said to bear speaker-oriented modality.

Semantically speaking, disjunct expresses three aspects of subjective modality: speakers' cognition, affect, or style (cf. Hyland, 1999; Conrad \& Biber, 2000; Biber et al., 2000; Biber, 2006). Cognition is the speaker's commitment to the truth of proposition, affect is the speaker's emotional attitude toward the utterance content, and style is the speaker's manner or perspective of presenting information. Among them, affect by its very nature is the most salient aspect of subjectivity, since it pertains to speakers' feeling and emotion. With this consideration, this study singles out the use of affective disjunct as the focus of investigation.

Previous studies in social and cultural perspectives have dealt with the social functions of modal devices, such as expressing politeness (Lakoff, 1972; Perkins, 1983; Brown \& Levinson, 1987; Allan, 1998), marking power (Kress \& Hodge, 1979; Fairclough, 1989; Hoye, 1997) and functioning as sociolinguistic markers (Perkins, 1983; Macaulay, 2002). Also notably, studies have shown that there are cross-cultural, especially cross-linguistic differences in the use of modal devices (Hoye, 1997; Aijmer, 2002; Vold, 2006). There are also within-language differences in the use of modal devices between users from different cultures, especially the use of subjective-modality devices (YANG, 2013). Yet in YANG's (2013) study, affective disjunct is not treated as a unique subjective-modality category and its usage in relation to culture is not well differentiated from other modal devices. As a further pursuit in this line, the present study aims to describe and explain the differences in the use of English affective disjunct between users from different cultural backgrounds, and it takes American versus Chinese cultural backgrounds for illustration. 


\section{Data and Method}

It is widely accepted that American and Chinese cultures have noticeable differences in many aspects, so they are chosen for illustration. Highlighting the anthropological aspect of culture is in agreement with the choice of national culture (big culture) as the unmarked object for cultural comparison. Controlled and comparable English texts written by advanced users of English from American versus Chinese cultural backgrounds were thus collected as data.

Comparability of the data is established on the fact that all the texts are of the same type-personal commentary in public media, and are concerned with similar subject matters (politics, economy, and current events). The nature of this specific discourse type implies a strong possibility to find frequent use of affective disjunct in the texts, since the discourse goal of commentary is to purposefully exert personal influence on the implied readership by expressing a comment, view, or opinion on a certain issue. These texts are assumed to be written by advanced English users (i.e., writers) since they appear in some renowned media and are free from linguistic errors. They are randomly sampled from openly available online media resources in China and U.S. respectively. The composition of the two datasets of comparable size is provided in Table 1.

Table 1

Composition of the Corpus

\begin{tabular}{llllll}
\hline & Data source & No. of texts & No. of words & $\begin{array}{l}\text { Range of text } \\
\text { length* }\end{array}$ & $\begin{array}{l}\text { Average text } \\
\text { length* }\end{array}$ \\
\hline $\begin{array}{l}\text { Chinese } \\
\text { Dataset }\end{array}$ & $\begin{array}{l}\text { Beijing Review, China Daily, People Daily, } \\
\text { Shanghai Daily, Xinhua-net }\end{array}$ & 100 & 82,375 & $403 \sim 2,133$ & 824 \\
$\begin{array}{l}\text { American } \\
\text { Dataset }\end{array}$ & $\begin{array}{l}\text { Los Angeles Times, the International Herald } \\
\text { Tribune, New York Times, the Wall Street } \\
\text { Journal, Washington Post }\end{array}$ & 100 & 76,995 & $302 \sim 1,860$ & 770 \\
Total & & 200 & 159,370 & $302 \sim 2,133$ & 797 \\
\hline
\end{tabular}

Note. $*=$ measured by word number.

The selected texts all appear in columns titled "commentary", “comment”, “view”, or "opinion”, and their content is checked to ensure they belong to personal commentary. No two texts are written by the same author(s), which minimizes the idiosyncratic effect. The random selection also minimizes the effect of author's gender. The name of each author is checked against some openly available biographical information to ensure that he or she is a Chinese or an American respectively.

Some texts in the Chinese dataset might be subject to the potential effect of translation, since there is still possibility that some of them may have been translated into English from a Chinese original. Translating may impact the selection of linguistic features. However, even if this could be the case, the Chinese-English bilingual translator is very likely a Chinese English as a second language (ESL) user rather than an English as a native language (ENL) user. Moreover, the assumption is generally maintained that non-literary translation should strive to be loyal to the original in terms of structure and meaning. Meanwhile, translation can serve a positive purpose, since competent translators can ensure the grammatical well-formedness of the target text. Nevertheless, no evidence is available for the conjecture that translation has ever played any role in these texts.

All being considered, the linguistic data can well meet the need of comparison. Subsequently, the affective disjuncts, if any, used in each text are identified and marked in bold-face following a rigorous scheme involving both structural and semantic considerations. Yet words occurring in reported talk are excluded. A 
research assistant has re-checked the identified tokens of affective disjunct. Where controversy arises, we make rigorous re-examination and thorough discussion until full agreement is reached.

\section{Results and Discussion}

\section{General Statistical Results}

According to the method described above, altogether 59 affective disjunct items are identified from the two datasets, listed as follows ${ }^{1}$ :

luckily, marvelously, memorably, more important, more importantly, remarkably, justly, hopefully, worse, naturally, fortunately, mysteriously, essentially, above all, allegedly, amazingly, arguably, as important, blindingly, blissfully, ironically, just as well, not unreasonably, notably, notoriously, catastrophically, cheaply, dangerously, deservedly, dizzyingly, famously, oppressively, paradoxically, pathetically, perfect, perfectly, prematurely, seductively, seemingly, strangely, stunningly, surprisingly, thankfully, to no one's surprise, typically, unbelievably, uncommonly, unexpectedly, unfairly, unfortunately, uniquely, unusually, unwisely, unwittingly, OK, oops, yes, well (int.), oh.

A comparison for difference in the distribution of these affective disjuncts is then made between the two datasets. The results are described in Table 2.

Table 2

Distribution of Affective Disjunct in the Two Datasets

\begin{tabular}{lll}
\hline Affective disjunct & Chinese dataset & American dataset \\
\hline Type & 13 & 59 \\
Token & 35 & 136 \\
Average token per text & 0.35 & 1.36 \\
Overall occurrence rate & $0.04 \%$ & $0.18 \%$ \\
\hline
\end{tabular}

This table shows clearly asymmetrical distribution of affective disjunct between the two datasets: Affective disjunct is used more frequently in the American dataset than in the Chinese dataset. Both the types and tokens of affective disjunct in the American dataset far outnumber those in the Chinese dataset. Difference between them is also found in terms of the average token per text ( 0.35 vs. 1.36) and overall occurrence rate as measured against the dataset size ( $0.04 \%$ vs. $0.18 \%)$.

To technically construe this statistical contrast, a paired samples t-test regarding the frequency of affective disjunct across the two datasets is conducted. In this test, the types of affective disjunct are treated as the individuals of a sample, the two datasets are treated as the independent variables, and the token number of each type in either dataset is treated as the dependent variable. This statistical test is a more reliable method of judging the differences in frequency, since it takes into account both the type number and the token number of affective disjunct when the sizes of the two datasets are comparable. The results show that the significance level is .002 $(<.05)$. Therefore, the overall difference in frequency is highly significant. In other words, the American authors use affective disjunct far more frequently in commentary texts than do the Chinese authors.

Now that the differences have emerged from controlled data, it is plausible to look beyond the discourse context for some factors that are possibly involved, especially those concerning the authors and the

\footnotetext{
${ }^{1}$ All these items appear in periphery or detached positions rather than phrase-internal positions.
} 
socio-cultural contexts of text production. For a start, the potential difference in English proficiency between the two groups of authors might be at play, since the American authors as native speakers may be assumed to be more proficient in English than the Chinese authors as non-native speakers. Supposing so, the American authors might be better equipped with lexical competence regarding affective disjunct. However, this potential difference, even if existent, can only lead to a quite moderate effect. As the discourse type and linguistic characteristics of all those texts show, they are produced by advanced users of English. It is very likely that authors from both groups have acquired most, if not all, of those lexical items used as affective disjunct. Actually, most of these lexical items are high-frequency words which are in the repertoire of ordinary speakers of English. On this account, it is likely that the two groups of advanced users have no significant difference in their lexical competence in using affective disjunct. Secondly, the sociopolitical context of discourse production might have a bearing upon the differences under discussion. Discourse appearing in the media tends to be sanctioned institutionally and is subject to the dissemination of ideology (Fairclough, 1989). Such impact is readily felt in the choice of lexis. The use of affective disjunct, which could be value-laden, might thus be regulated. However, in the data collection, effort is purposefully taken to downplay the influence of sociopolitical context by selecting texts of personal instead of institutional commentary (e.g., editorial), so that sociopolitical factors do not seem pertinent enough to the above differences.

As culture (i.e., users' cultural background) is employed here as the exploratory variable, the above differences can be discussed and understood in this light. To explore the potential relation of the differences in the use of English affective disjunct to the cultural differences between the American users and Chinese authors, we need to: (1) address the function of using affective disjunct in these texts, since the meaning-making aspect of language use is most likely to be shaped by culture (Hewitt, 1991) and (2) operationalize the construct of culture to encompass some cultural aspect(s) whose relation with language use is empirically observable. In what follows, we provide a functional analysis of the use of affective disjunct, and then propose an interpretation of the above differences in terms of cross-cultural differences with reference to a theoretical framework that addresses aspects of culture and language use.

\section{Functional Analysis of the Use of English Affective Disjunct}

A functional analysis of discourse devices can lead to a fuller understanding of how users achieve communicative goals (Cheshire, 2007). The use of affective disjunct is in fact amenable to a functional interpretation in terms of involvement, i.e., the participation of subjectivity and the achievement of intersubjectivity. There has been empirical evidence for the involvement function of subjective expressions in discourse (Crismore \& VandeKopple, 1997; Lewin, 2005; Hyland, 1998, 1999, etc.).

As its name suggests, affective disjunct is used to express speakers' affective stance toward information, which is a key aspect of the personal as well as interpersonal meaning of language use. It packages the target information with an external message and suggests the way readers are expected to make sense of the information (see Examples (4)-(5)).

Example (4) More importantly, though risks can sometimes be averted, they will never be totally eliminated.

Example (5) There are hopefully some bilateral meetings at the sidelines of the summit to discuss bilateral... issues.

As the semantic content of these affective disjuncts demonstrates, they are not concerned with the truth of 
information per se, but with speakers' affective comment on the discourse referent denoted by information. It is clear that affective disjunct as such is hearable to have an involvement function, since affect is subjective rather than objective and it can humanize and personalize an utterance and the information being conveyed. Be it positive or negative, the affect being expressed is an affirmation of the presence of authorship (Lyons, 1995). By conveying personal feelings in information, the author is personally involved in the communicative event. Here, with the use of more importantly and hopefully, the authors impose an external feeling on the information and manifest their emotional investment in its presentation, indicating the overt presence of subjectivity.

Such personal involvement is also interpersonal. By projecting himself or herself into the information, the author also expresses his or her willingness to establish an emotional bond with the audience. From a symbolic interactionist perspective, affective expression contributes to the attainment of intersubjectivity in interaction (Turner, 2004, Martin \& White, 2005). The use of affective disjunct is arguably a way of emotionally involving discourse participants, stressing their mutual presence and foregrounding their emotional connectedness.

As for personal commentary discourse in particular, affective disjunct is a means of cooperating with the implied reader to help him or her grasp the author's view more directly. By presenting one's stance toward information, the author shortens the distance from the implied reader, to the extent that using affective disjunct functions as an involvement strategy. The use of strangely in Example (6), for instance, can particularly illustrate this effect:

Example (6) Connect the dots and you will find there is a need for a fix to a crisis that, strangely, is not caused by smaller harvests.

Here with strangely, the author unpacks a feeling-strange attitude toward the information "a crisis is not caused by smaller harvests”. Positioned as a disjunct, strangely highlights the author's viewpoint and thus adds to the achievement of subjectivity and intersubjectivity.

Involvement by using affective disjunct is also understood as a metadiscoursal function in presenting information as discussed in the literature. Connor (1996) has defined metadiscourse as "the linguistic material in texts that does not add anything to the propositional content but helps the reader organize, interpret, and evaluate the information" (p. 94). As also argued by Hyland (2005), metadiscourse is "the cover term for the self-reflective expressions used to negotiate interactional meanings in a text, assisting the writer (or speaker) to express a viewpoint and engage with readers...” (p. 37). Affective disjunct, in particular, fits with such descriptions and counts as a metadiscoursal device used for evaluating information. By modifying information with a stance and assigning a value position, affective disjunct becomes a crucial metadiscoursal device for constructing writer and reader identity (Silver, 2003).

The metadiscoursal function is clearly interpersonal. By voicing an affective comment, the author not only manifests himself or herself, but also manifests the reader by indicating the way to understand the content of the primary message and his or her goal (Crismore, 1989). In an abstract sense, metadiscourse attests to the author's desire for control of the discourse and readership (Silver, 2003). This property is highly indicative of the interpersonal involvement in discourse. Therefore, the difference in the use of affective disjunct between the American authors and the Chinese authors can be functionally interpreted as a difference in the degree of tendency to involve in discourse.

Notably, affective disjunct that appears in clause- or sentence-initial position, i.e., the left periphery, can best illustrate authors' direction of readers' interpretation, since it projects an interpretive frame from the very start of information unfolding. More examples are such as: 
Example (7) Luckily, Assembly Member Nicole Parra (D-Hanford) has a solution for all of this: consumer choice.

Example (8) Ironically, we know how to end life painlessly.

Example (9) Unfortunately, one of the ways Mr. Friedman chose to illustrate this idea was by extolling the packaging...

In these cases, the whole of the succeeding information is framed by the feeling of "luckiness", "irony", or "misfortune". By putting the affective comment first, the author utilizes a sentence-level deductive strategy to subordinate the propositional information to an attitude, and expects the audience to interpret the information from the perspective proffered. This pattern of placing affective disjunct in the initial position is observed to be more typical of the American authors. Such a difference further reveals the difference between the American and Chinese authors in the degree of emphasizing interpersonal involvement in communicating information.

Moreover, the American authors use affective disjuncts that express a strong emotion more than the Chinese authors do. This is particularly characterized by the use of those items expressing a negative feeling, like pathetically and paradoxically. These high-value disjuncts contain an intense modal force and play up the author's feeling. By exerting a strong affective control on the information, the author also exerts strong affective imposition on the reader, influencing his or her way of feeing about the information. The reader is expected to share the author's feeling and establish affective solidarity. Inevitably, the reader may subscribe to the author's comment or may be activated to respond affectively in alternative ways. In such circumstances, the reader is in no way a passive reader who just sits back and remains uninvolved. Compared with the American authors, the Chinese authors tend to express their affective comment moderately and show a lower degree of involvement in this respect.

Among the affective disjuncts used in the data, there is a special subset that carries a strong exclamatory tone and that does not occur frequently in written English discourse. These disjuncts include oh, OK, oops, well, and yes, which have no referential meaning but are straightforward conveyors of conventional human emotions. They are identified solely in the American dataset (26 tokens), reflecting the difference in involvement (see Examples (10)-(11)).

Example (10) Oh, Darfur gets plenty of news coverage from sympathetic reporters sickened by the carnage and devastation...

Example (11) Central banks had learned to tame inflation. Politicians had learned to appreciate the folly of price controls. Thanks to the economics profession, policymakers had grown wiser. Well, inflation has returned.

These exclamatory disjuncts are iconic reflections of authors' emotional response. Meanwhile, they overtly signal interpersonal involvement in discourse. According to Schiffrin (1987), the use of oh, for example, displays speaker and addressee in participation frameworks and displays speaker-addressee alignment toward each other. Likewise well functions to catch the addressee's attention to the inconsonance between expectation and information and involves the addressee to construct coherence, i.e., assigning a participant role to the addressee (Schiffrin, 1987).

The noticeable interpersonal effect of exclamatory disjuncts also derives from the feeling of intimacy and affective bond enhanced by their oral characteristics (Blum-Kulka, 1990). There is strong linkage between orality, informality, and closeness. Oral linguistic features in written discourse contexts de-formalize and interpersonalize information presentation, contributing to "a feeling of joint interpersonal 
involvement” (Kramsch, 1998, p. 47) and affective interaction between writers and readers, since these features allow readers to witness writers' act of emotional disclosure as if face to face. Naturally, using exclamatory disjuncts foregrounds the affective persona of the discourse participants and builds their affective solidarity. The exclusive use of these disjuncts by the American authors in the data marks their stronger inclination to initiate involvement.

In sum, the American authors use English affective disjunct more intensively and extensively than do the Chinese authors. The functional analysis of affective disjunct shows that these differences reflect a difference in the degree of involvement in discourse between the two groups of authors. Subsequently, this difference in involvement is discussed from a cross-cultural perspective.

\section{Involvement and Solidarity Face System}

To discuss the relation of involvement to culture, we draw upon R. Scollon and S. W. Scollon's (1995/2001) theoretical framework on culture as discourse system, which incorporates insights from Gumperz (1982), Chafe (1982), and Tannen (1989). This framework describes the systematic relationship between discourse and the face systems of culture, thus offering explanation for differences in discourse from the perspective of users' cultural background. When the involvement function of affective disjunct is analyzed within this framework, the relevance of the cultural background of the users to an explanation of the above results is likely to emerge.

The major content of the framework is sketched in Figure 1:

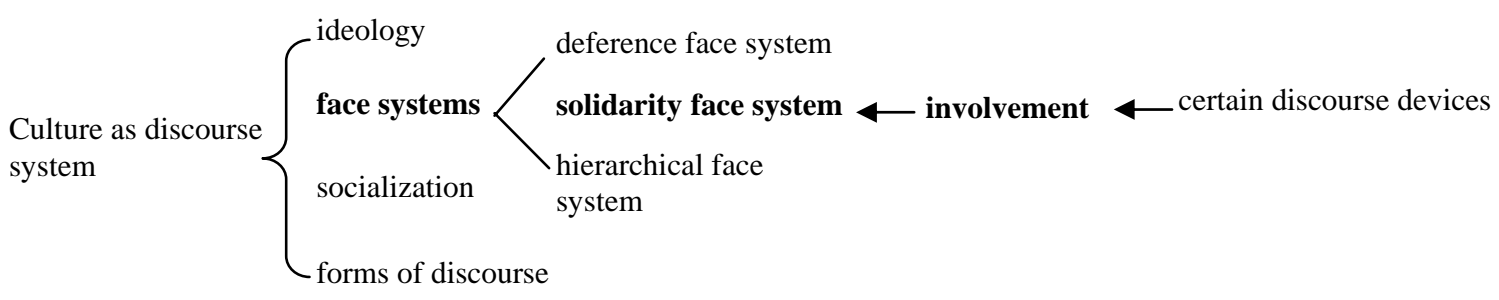

Figure 1. Involvement and culture as discourse system.

In this framework, put briefly, face system is one of the four components belonging to culture as discourse system; solidarity face system is one of the three types of face system; involvement is the face (strategy) characteristic of solidarity face system; and certain discourse devices have an involvement function in given contexts. An application of this framework can reveal how the use of involvement devices like affective disjunct is connected to culture.

The face systems of culture describes the general pattern of how social interactants (e.g., speaker and addressee) are relationally organized, and a specific face system is abstracted from the "general and persistent regularities in face relationships” exhibited in interaction (R. Scollon \& S. W. Scollon, 1995/2001, p. 42). A face system is defined by two major parameters, power (i.e., the vertical disparity between interactants as is socially determined) and distance (i.e., the horizontal/dialogical distance between interactants). Along these parameters are identified three major face systems: solidarity, deference, and hierarchical face systems. They are idealized ways of designating the regularities of interactional patterns and usually combine with each other in different configurations to form the specific face systems of specific cultures. Therefore, we talk of the face systems (plural) instead of face system (singular) of a culture. The influence of face systems on cultural members' discourse is directly analyzable, and a focus on face systems can be conceptualized as a linguistic 
approach to the cultural background of language users. In fact, as R. Scollon and S. W. Scollon (1995/2001) indicate, face system is a major locus of cross-cultural differences in language use.

As Figure 1 and Table 3 show, it is solidarity face system that is essentially characterized by involvement. It presupposes that discourse participants manifest themselves as being in symmetrical positions and use involvement face strategy to minimize discoursal distance. Solidarity face system is widely reflected in a variety of non-hierarchical discourses (e.g., personal commentary discourse) in many cultures and the corresponding involvement strategy is frequently adopted.

Table 3

Solidarity Face System in Comparison With Other Face Systems

\begin{tabular}{|l|l|l|}
\hline Face system & Parameters & Face (strategy) \\
\hline Solidarity & -P, $-\mathrm{D}$ & involvement \\
\hline Deference & $-\mathrm{P},+\mathrm{D}$ & independence \\
\hline Hierarchical & $+\mathrm{P},+/-\mathrm{D}$ & upward independence downward involvement \\
\hline
\end{tabular}

Notes. $\mathrm{P}=$ power; $\mathrm{D}=$ distance.

Involvement is on the one hand an aspect of face, which is the public manifestation of social interactant's situated self-image (Goffman, 1955; Brown \& Levinson, 1987). Involvement face in linguistic interaction orients to interactants' situated identity as participants (speaker/writer or addressee/reader) and their connection to the discourse content and to each other (also see Chafe, 1985), thus opposed yet complementary to independence face, which is marked by detachment. Involvement is claimed to have a universal psychological basis, and reflects the universal human needs to act together (Besnier, 1998). It is concerned with "the person's right and need to be considered a normal, contributing, or supporting member of society" (R. Scollon \& S. W. Scollon, 1995/2001, p. 36) and built upon "an internal, even emotional connection individuals feel which binds them to other people as well as to places, things, activities, ideas, memories, and words” (Tannen, 1989, p. 12).

Involvement is on the other hand a face strategy, which entails the shortening of dialogic distance and encompasses the devotion of subjectivity. It can be enacted by a variety of devices. As analyzed previously, the use of affective disjunct is hearable as an involvement strategy by virtue of constructing an active role for discourse participants. Personal commentary as written discourse might be less interactive than spoken discourse, yet the use of affective disjunct can facilitate interactional involvement and help achieve the goal of getting writers' claims ratified by the readership. The use of affective disjunct arguably reflects the presence of solidarity face system.

In the data, as the American authors draw on affective disjunct as an involvement resource more intensively and extensively than the Chinese authors do, readers may experience more informality, closer distance, more co-participation and more "silent dialogues" with the author when reading the texts in the American dataset. Hence, an underlying explanation for the cross-cultural differences can be advanced: The difference in the degree of involvement with regard to the use of affective disjunct is interpreted as a difference in the degree of the manifestation of solidarity face system. It is plausible to claim that the American authors are motivated by solidarity face system more than are the Chinese authors when constructing written personal commentary discourse.

This cross-cultural difference in solidarity face system is corroborated by some other studies on the differences between speakers from American versus Chinese cultural backgrounds. The Americans are 
generally found to assert a higher need for both "self face" and "other face" than the Asians in communication (Ting-Toomey \& Oetzel, 2003), and they are also found to prefer addressing each other by first name (Brown \& Ford, 1961; Ervin-Tripp, 1972), which reflects the "solidarity semantic" (Brown \& Gilman, 1960). Since solidarity is concerned with the equality in the participation in discourse, the deeper imprint of solidarity face system in the American users reflects their need of emphasizing egalitarianism (R. Scollon \& S. W. Scollon, 1995/2001, p. 131). Naturally, this emphasis has significant consequences in the choice of involvement strategies. By contrast, the less adoption of solidarity face system by the Chinese users is consistent with Gudykunst and Ting-Toomey's (1992, p. 225) argument that the Chinese culture's collectivist orientation constrains its members from presenting themselves boldly. Such taciturnity is tantamount to the emotional reservation, introversion, and self-constraint that characterize the national disposition of China and even the other Asian societies (Hall, 1976; Bond \& Hwang, 1986; Young, 1994; Renkema, 2004).

We cannot indiscriminately generalize this cross-cultural difference to all spheres of language use, since this difference might be overridden by some other discourse factors. Nevertheless, it is still tenable to proffer the claim that the use of English affective disjunct in personal commentary discourse reflects the difference in solidarity face system between American and Chinese users.

\section{Conclusions}

In this study, differences in the use of English affective disjunct found between American and Chinese users are related to a cross-cultural difference between the two groups: American users are influenced more by solidarity face system than are the Chinese users. This relation is established by a functional analysis of the use of affective disjunct. Affective disjunct is laden with subjectivity and thus can build and enhance involvement, which is the defining feature of solidarity face system.

Language use tends to be shaped by culture and speakers from different cultural backgrounds tend to use language in different ways. In studying differences in discourse, it is useful to take culture as a conceptual shorthand or a heuristic concept. However, the relationship between language use and culture may be latent and we may not know how to construe our discoveries about it. As this study shows, a valid cross-cultural analysis can be informed by theoretical frameworks that contain operationalized constructs dealing with aspects of culture and discourse features. For instance, it is advisable to focus on the face systems of culture while examining cross-cultural differences in discourse, since face system has systematic, though not straightforward, influence on discourse. The internal construction of the face systems of a culture, like linguistic structure, is relatively constant, despite the superficial modifications brought by the increasing cultural contact in the contemporary world. The influence of face systems on discourse is relatively regular. Generally speaking, the composition of the face systems of one culture is quantitatively different from that of others. With a focus on the face systems, the analysis of discourse features can concentrate on their face function and then the underlying cultural influence could be revealed.

Our findings have some theoretical implications for the conceptualization of cultural influence on discourse. Differences in discourse underlain by cultural differences tend to be gradient. For instance, the American authors and the Chinese authors use involvement devices like English affective disjunct differently, yet the differences are only quantitative. Especially for cultural universals, the difference is usually a matter of continuity rather than binary opposites, as reflected in asymmetrical frequencies and distribution of linguistic devices. Culture is only one of the factors that may have potential influence on speaker's choice in 
communication, and there is mediation between cultural influence and individual agency in specific contexts. The different cultural patterns of discourse do not suggest prescriptive norms but relative tendencies.

This study can also add to our understanding about the analytical validity of face strategies, especially involvement, in written discourse. Interactivity not only is manifested in face-to-face talk, but also exists in written communication. Written discourse is dialogic by nature since it contains the anticipated contribution from the implied addressee (Bakhtin, 1981; Cook, 1994; Coulthard, 1994; Swales, 1990). Naturally, written discourse is a locus of face negotiation. As is generally recognized, discourse encapsulates two interrelated levels of function: information and relationship. In spoken and written discourses alike, interpersonal meanings are negotiated, so the interactional categories like face and involvement can be applied in the analysis of both oral and written discourse features.

\section{References}

Aijmer, G. (2002). Modal adverbs of certainty and uncertainty in an English-Swedish perspective. In H. Hasselgard (Ed.), Information structure in a cross-linguistic perspective (pp. 97-112). Amsterdam: Rodopi B. V.

Allan, K. (1998). Moods, clause types, and speech acts. In J. L. Mey \& R. E Asher (Eds.), Concise encyclopedia of pragmatics (pp. 597-599). Oxford: Elsevier Science Ltd..

Atkinson, D. (2004). Contrasting rhetorics/contrasting cultures: Why contrastive rhetoric needs a better conceptualization of culture. Journal of English for Academic Purposes, 3, 277-289.

Bakhtin, M. M. (1981). The dialogic imagination. Austin: University of Texas Press.

Barron, A. (2005). Variational pragmatics in the foreign language classroom. System, 33, 519-536.

Besnier, N. (1998). Involvement. In J. L. Mey \& R. E. Asher (Eds.), Concise encyclopedia of pragmatics (pp. 407-409). Oxford: Elsevier Science Ltd..

Biber, D. (2006). Stance in spoken and written university registers. Journal of English for Academic Purposes, 5, 97-116.

Biber, D., Johansson, S., Leech, G., Conrad, S., \& Finegan, E. (2000). Longman grammar of spoken and written English. Beijing: Foreign Language Teaching and Research Press.

Blum-Kulka, S. (1990). You don't touch lettuce with your fingers: Parental politeness in family discourse. Journal of Pragmatics, 14, 259-288.

Bond, M. H., \& Hwang, K. K. (1986). The social psychology of Chinese people. In M. H. Bond (ed.), The psychology of the Chinese people (pp. 213-266). Hong Kong: Oxford University Press.

Bourdieu, P. (1984). Distinction: A social critique of the judgment of taste. Cambridge, Mass.: Harvard University Press.

Brown, G., \& Levinson, S. C. (1987). Politeness: Some universals in language usage. Cambridge: Cambridge University Press.

Brown, R., \& Ford, M. (1961). Address in American English. Journal of Abnormal and Social Psychology, 62, 454-462.

Brown, R., \& Gilman, A. (1960). The pronouns of power and solidarity. American Anthropologist, 4(6), 24-29.

Buysschaert, J. (1982). Criteria for the classification of English adverbials. Brussels: Koninklijke Academic.

Chafe, W. L. (1982). Integration and involvement in speaking, writing, and oral literature. In D. Tannen (Ed.), Spoken and written language: Exploring orality and literacy. Norwood, N.J.: Ablex.

Chafe, W. L. (1985). Linguistic differences produced by differences between speaking and writing. In D. R. Olson, N. Torrance, \& A. Hildyard (Eds.), Literacy, language and learning: The nature and consequences of reading and writing (pp. 105-123). Cambridge: Cambridge University Press.

Cheshire, J. (2007). Discourse variation, grammaticalization and stuff like that. Journal of Sociolinguistics, 2, 155-193.

Chomsky, N. (1984). Lectures on government and binding: The Pisa lectures. Dordrecht, Holland: Foris Publications.

Connor, U. (1996). Contrastive rhetoric: Cross-cultural aspects of second-language writing. Cambridge: Cambridge University Press.

Conrad, S., \& Biber, D. (2000). Adverbial marking of stance in speech and writing. In S. Hunston \& G. Thompson (Eds.), Evaluation in text. Oxford: Oxford University Press.

Cook, G. (1994). Discourse and literature. Oxford: Oxford University Press.

Coulthard, M. (1994). On analyzing and evaluating written text. In M. Coulthard (ed.), Advances in written text analysis. London and New York: Routledge.

Crismore, A. (1989). Talking with readers: Metadiscourse as rhetorical act. New York: Peter Ling. 
Crismore, A., \& VandeKopple, W. J. (1997). The effects of hedges and gender on the attitudes of readers in the United States toward material in a science textbook. In A. Dusak (Ed.), Culture and styles of academic discourse (pp. 223-47). Berlin: Mouton de Gruyter.

Ervin-Tripp, S. (1972). Sociolinguistics. In J. Pride \& J. Holmes (Eds.), Sociolinguistics (pp. 225-240). Harmondsworth: Penguin. Fairclough, N. (1989). Language and power. London and New York: Longman.

Fetzer, A. (2004). Recontextualizing context: Grammaticality meets appropriateness. Amsterdam/Philadelphia: John Benjamins Publishing Company.

Geertz, C. (1973). The interpretation of cultures. New York: Basic Books.

Geertz, C. (1984). Anti anti-relativism. American Anthropologist, 86, 263-278.

Goffman, E. (1955). On face-work: An analysis of ritual elements of social interaction. Psychiatry: Journal for the Study of Interpersonal Processes, 18(3), 213-231.

Goodenough, W. (1981). Culture, language and society. Menlo Park, CA: Benjamin/Cummings.

Greenbaum, S. (1969). Studies in English adverbial usage. London: Longman.

Gudykunst, W. B., \& Ting-Toomey, S. (1988). Verbal communication styles. In W. B. Gudykunst \& S. Ting-Toomey (Eds.), Culture and interpersonal communication (pp. 99-115). Newbury Park, CA: Sage.

Gumperz, J. J. (1982). Discourse strategies. Cambridge: Cambridge University Press.

Hall, E. T. (1976). Beyond culture. New York: Anchor Press.

Halliday, M. A. K. (1978). Language as social semiotic: The social interpretation of language and meaning. London: Arnold.

Halliday, M. A. K. (1994). An introduction to functional grammar. London: Arnold.

Hewitt, J. P. (1991). Self and society: A symbolic interactionist social psychology. Boston: Allyn and Bacon.

Hofstede, G. (1980). Culture's consequences: International differences in work-related values. Beverly, CA: Sage.

Hoye, L. (1997). Adverbs and modality in English. New York: Addison Wesley Longman Limited.

Hunston, S., \& Thompson, G. (Eds.). (2000). Evaluation in text: Authorial stance and the construction of discourse. Oxford: Oxford University Press.

Hyland, K. (1998). Persuasion and context: The pragmatics of academic metadiscourse. Journal of Pragmatics, 30, 437-455.

Hyland, K. (1999). Disciplinary discourses: Writer stance in research articles. In C. N. Candlin \& K. Hyland (Eds.), Writing: Texts, processes and practices. London: Longman.

Hyland, K. (2005). Metadiscourse. London and New York: Continuum.

Jacobson, S. (1964). Adverbial positions in English. Stockholm: Studentbok.

Jacobson, S. (1978). On the use, meaning and syntax of English preverbal adverbs. Stockholm: Almqvist \& Wiksell International.

Kiefer, F. (1998). Modality. In J. L. Mey \& R. E. Asher (Eds.), Concise encyclopedia of pragmatics (pp. 591-597). Oxford: Elsevier Science Ltd..

Kramsch, C. (1998). Language and culture. Oxford: Oxford University Press.

Kress, G., \& Hodge, R. (1979). Language as ideology. London: Routledge \& Kegan Paul.

Lakoff, R. (1972). The pragmatics of modality. Papers from the Eighth Regional Meeting of the Chicago Linguistic Society (Vol. 8, pp. 229-246), Department of Linguistics, University of Chicago, Chicago.

Lewin, B. A. (2005). Hedging: An exploratory study of authors' and readers' identification of 'toning down' in scientific texts. Journal of English for Academic Purposes, 4, 163-178.

Lyons, J. (1995). Linguistic semantics: An introduction. Cambridge: Cambridge University Press.

Macaulay, R. (2002). Extremely interesting, very interesting, or only quite interesting? Adverbs and social class. Journal of Sociolinguistics, 3, 398-417.

Malinowski, B. (1923). The problem of meaning in primitive languages. Supplement to C. K. Ogden \& I. A. Richards (Eds.), The meaning of meaning (pp. 296-336). San Diego, New York, and London: Harcourt Brace Jovanovich.

Martin, J. R., \& White, P. R. R. (2005). The language of evaluation: Appraisal in English. New York: Palgrave Macmillan.

Palmer, F. R. (2001). Mood and modality (2nd ed.). Cambridge: Cambridge University Press.

Perkins, M. R. (1983). Modal expressions in English. Norwood, N.J.: Ablex Publishing Corporation.

Quirk, R., Greenbaum, S., Leech, G., \& Svartvik, J. (1985). A comprehensive grammar of the English Language. London: Longman.

Renkema, J. (2004). Introduction to discourse studies. Amsterdam and Philadelphia: John Benjamins.

Schiffrin, D. (1987). Discourse markers. Cambridge: Cambridge University Press.

Scollon, R., \& Scollon, S. W. (1995/2001). Intercultural communication: A discourse approach. Oxford: Blackwell. 
Silver, M. (2003). The stance of stance: A critical look at ways stance is expressed and modeled in academic discourse. Journal of English for Academic Purposes, 2, 359-374.

Spencer-Oatey, H. (Ed.). (2000).Culturally speaking: Managing rapport through talk across cultures. London: Continuum. Swales, J. M. (1990). Genre analysis. Cambridge: Cambridge University Press.

Tannen, D. (1989). Talking voices: Repetition, dialogue, and imagery in conversational discourse. Cambridge: Cambridge University Press.

Ting-Toomey, S., \& Oetzel, J. G. (2003). Cross-cultural face concerns and conflict styles. In W. B. Gudykunst (Ed.), Cross-cultural and intercultural communication (pp. 127-147). Thousand Oaks, C.A.: Sage.

Turner, J. H. (Ed.). (2004). The structure of sociological theory. Beijing: Peking University Press.

Vold, E. T. (2006). Epistemic modality markers in research articles: A cross-linguistic and cross-disciplinary study. International Journal of Applied Linguistics, 16(1), 61-87.

Whorf, B. L. (1956). Language, thought, and reality: Selected writings of Benjamin Lee Whorf. Cambridge, Mass.: The MIT Press.

Wierzbicka, A. (1985). Different cultures, different languages, different speech acts. Journal of Pragmatics, 9, 145-178.

YANG, Z. (2013). Cultural differences in the use of English modal adjunct. Hangzhou: Zhejiang University Press.

Young, L. W. L. (1994). Crosstalk and culture in Sino-American communication. Cambridge: Cambridge University Press. 